This item was submitted to Loughborough's Research Repository by the author.

Items in Figshare are protected by copyright, with all rights reserved, unless otherwise indicated.

\title{
Comparison of noise impacts from urban transport
}

PLEASE CITE THE PUBLISHED VERSION

PUBLISHER

(c) Thomas Telford

VERSION

VoR (Version of Record)

LICENCE

CC BY-NC-ND 4.0

REPOSITORY RECORD

Frost, Matthew W., and Stephen G. Ison. 2019. "Comparison of Noise Impacts from Urban Transport". figshare. https://hdl.handle.net/2134/4331. 
This item was submitted to Loughborough's Institutional Repository (https://dspace.lboro.ac.uk/) by the author and is made available under the following Creative Commons Licence conditions.

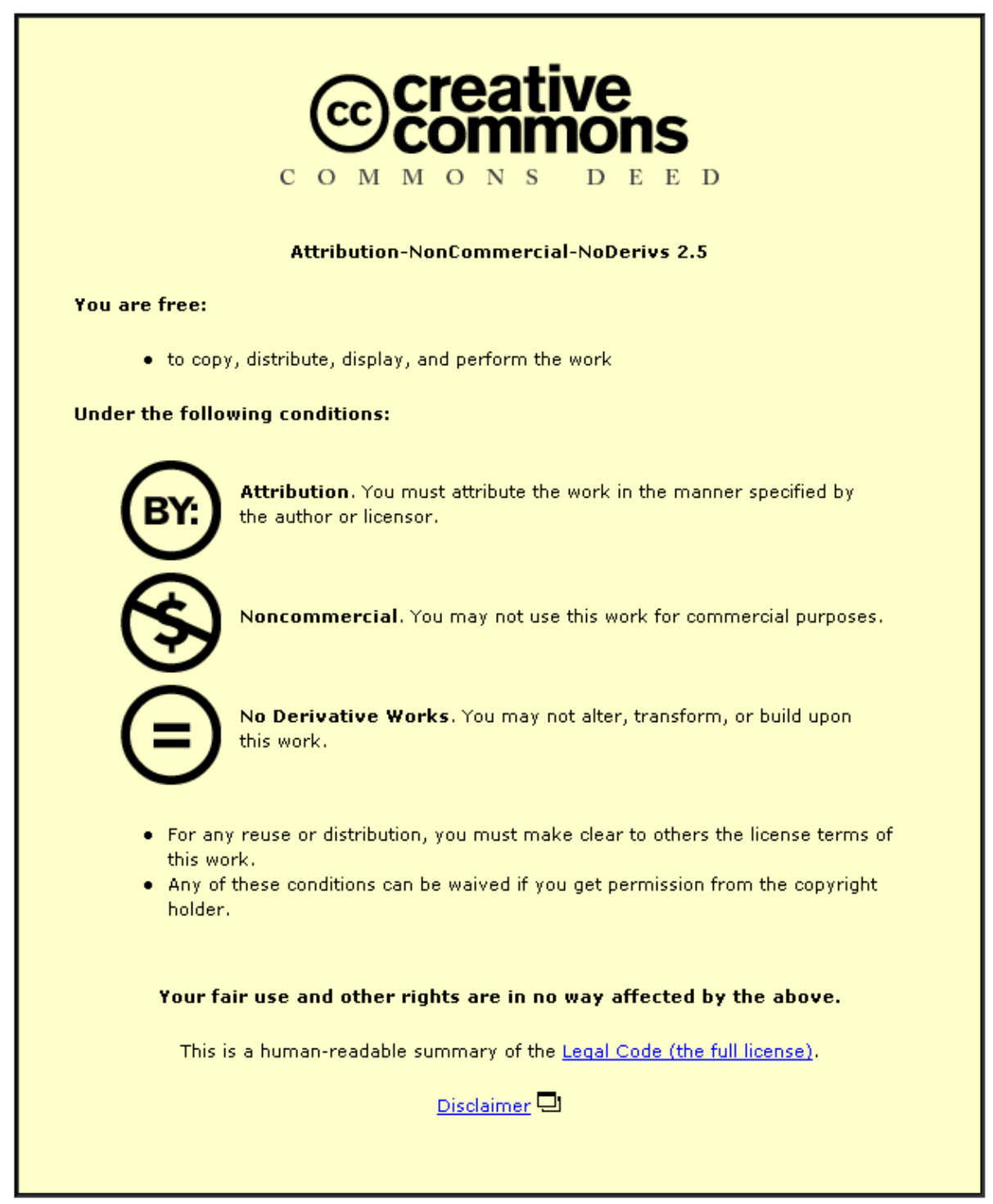

For the full text of this licence, please go to: http://creativecommons.org/licenses/by-nc-nd/2.5/ 


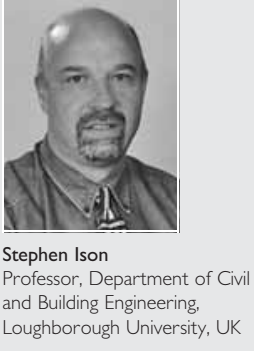

\section{Comparison of noise impacts from urban transport}

M. Frost BEng, PhD, MPWI and S. Ison MA, PhD, MCILT

When new transport schemes are considered, a key issue is the potential impact of noise. The reaction of people to noise however is both personal and subjective. Whereas all types of new urban transport scheme have noise evaluations, little work has been undertaken to date to compare the noise generated by the different modes of transport namely, a tram, car, bus and guided bus. The lack of such evaluations has implications for scheme perception when new modes are introduced, and such comparisons frequently form part of the public debate when systems are proposed. This paper outlines the assessment of noise and its measurement, reviews the limited published comparisons between modes and presents the results of an extensive series of noise measurements of in-service trams, buses and cars, (taken mainly within the Greater Nottingham area). The measurements have been made across a range of similar operational circumstances to allow comparison between the relative noise of particular modes. The paper concludes that from measurement across operational circumstances there should be little perceived difference in noise from buses and trams, but that proportionately cars can generate significant emissions.

\section{INTRODUCTION}

When new transport schemes are promoted a potential problem is their noise impact. However, the reaction of people to noise is both personal and subjective. Although all types of new urban transport scheme have noise evaluations undertaken to identify the areas where a change in environmental effects may occur, little work has been performed to date seeking to compare the noise generated between the various modes of transport, namely tram, car, bus and guided bus. The traditional noise assessments produced tend to be scheme and location specific and the parameters measured offer little scope for general comparison between modes.

The lack of such information can create difficulties in terms of the perception of schemes when new modes of transport are introduced, and such comparisons frequently form part of the public debate when systems are proposed. In Nottingham 'anti-tram' groups opposing the extension of the Nottingham Express Transit (NET) tram system have argued that the tram will be significantly noisier than a bus. The limited published work on the subject suggests however that buses generate similar levels of noise to trams. With proposals for tram schemes and guided buses becoming more common and increasing debate over the optimum mode, information on the relative effects of the modes is becoming increasingly important.

This paper compares the relative noise of different modes within an urban transport system. It describes the assessment of transport noise, its measurement and characteristics, and how these measurements are currently used in standards in the assessment of environmental impact. It briefly details the limited published comparisons in terms of mode and noise, and a methodology for measuring the comparative effects, based on that used for the assessment of rail vehicles. It also presents the results of an extensive series of noise measurements of trams, buses and cars taken within Greater Nottingham, covering a range of similar operational circumstances, in order to allow a comparison to be made between the relative noise levels of the various modes. These were then compared with previously published information and conclusions drawn as to the relative impact of each mode.

\section{BASIC NOISE CONCEPTS AND NOISE MEASUREMENT}

Noise is measured in units of decibels $(\mathrm{dB}(\mathrm{A}))$ which is a logarithmic ratio of the power or intensity of the sound weighted towards and assessed relative to the perception and threshold of human hearing. The ear can only resolve differences in noise to about $3 \mathrm{~dB}(\mathrm{~A})$. A $3 \mathrm{~dB}(\mathrm{~A})$ change in noise corresponds to a doubling in the power of the generated noise. A doubling in perceived loudness results from a $10 \mathrm{~dB}(\mathrm{~A})$ change in noise equating to over an eightfold increase in power.

Since environmental noise varies through time it is normally assessed during specific exposure periods (such as 0700 to $2300 \mathrm{~h}$ for daytime and 2300 to $0700 \mathrm{~h}$ for night-time exposure). For the evaluation of specific noise events these are normally measured solely over their duration. For long duration measurements the noise generated is expressed as a $\mathrm{La}_{(\mathrm{eq})}$ value, which equates to a constant value of noise or an average noise dose over the time period. Additionally within the time period instantaneous maximum or peak values are also assessed, $\mathrm{La}_{(\max )}$. It is these peaks that normally control the measured $\mathrm{La}_{(\mathrm{eq})}$ level, particularly in shorter duration measurements. In measurements of long duration, peaks, if they occur infrequently, tend to be lost within the average. To allow comparison between different magnitude and duration noise events a sound equivalence level (SEL) can be assessed. The SEL is the magnitude of noise in a $1 \mathrm{~s}$ period that 


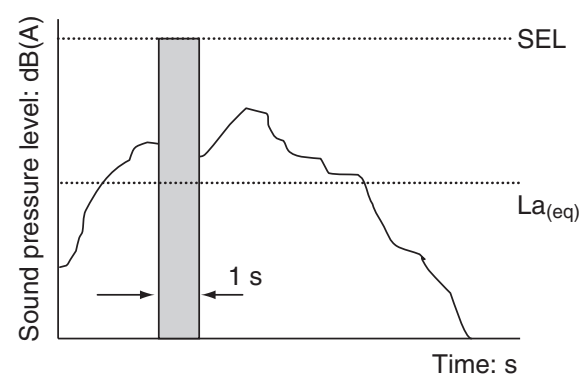

(a)

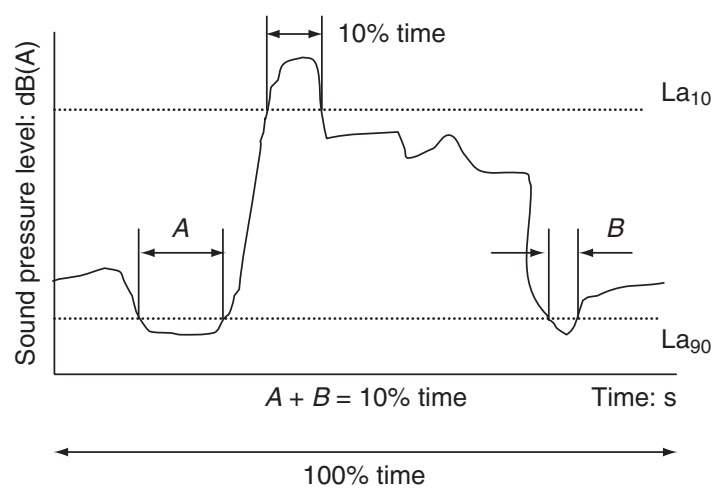

(b)

Fig. I. The conversion of noise data to: (a) La $($ eq) and SEL and (b) $\mathrm{La}_{10}$ and $\mathrm{La}_{90}$

contains the same power as the measured noise event. The above measurement parameters are defined in Fig. 1(a). ${ }^{1}$ It should be noted that the SEL value normally exceeds the $\mathrm{La}_{(\max )}$ value, since the SEL is dominated by the higher noise levels within any measured period. Therefore if noise readings of $10 \mathrm{~dB}(\mathrm{~A})$ less than the peak can be isolated for a noise event, representative SEL values for the event can be obtained.

Sometimes measurement of noise is described in percentage time exceedance levels over the measured duration. For example, traffic noise is often characterised as an $\mathrm{La}_{10}$ over a set time duration. This is the level of noise exceeded for $10 \%$ of the measured time period. Ambient noise is frequently expressed as $\mathrm{La}_{90}$ (level exceeded for $90 \%$ of the time period; Fig. 1(b)). ${ }^{1}$

The level of noise decays with distance from the source. For highly localised point sources of noise such as loudspeakers, noise decay is inversely proportional to the square of the distance (a doubling in distance results in a fourfold reduction in noise energy). For a line source (such as a train or road), noise decay is inversely proportional to distance (i.e. a doubling in distance halves the noise energy). Most transport noise is regarded as emanating from line sources.

Assessed noise at any point is also affected by factors that include temperature, pressure, wind direction and speed, ground surface effects, and adjacent buildings and their material properties.

\section{ELEMENTS AND CHARACTERISTICS THAT MAKE UP TRANSPORT NOISE}

There are three main components that contribute to the noise generated by the passage of any vehicle.

(a) Traction noise (engine noise, braking and other vehicular mechanical/operational noise).

(b) Wheel interface noise (the action of the tyre or wheel on the road or rail).

(c) Aerodynamic noise caused by the air displaced by the passage of the vehicle (although this only becomes significant at relatively high speed).

The magnitude and impact of each of these components within the noise generated varies as a function of vehicle type, speed, acceleration/deceleration, and motive power type. For example, a diesel bus generates more engine noise accelerating from a stop than travelling at constant speed. Tyre-road interaction gives limited noise from cars and buses on most road surfaces at lower speed, although it becomes more significant with speed. An electric tram, however, will generate more wheel-rail interface noise than engine noise across similar circumstances, with engine noise remaining relatively constant across the speed range. For diesel trains (Fig. 2) it is engine noise at low speed followed by interface noise, and then aerodynamic noise, that contribute the largest noise components as speed increases. ${ }^{2}$ Although the engine noise (traction) data in Fig. 2 (based on Ref. 2) are not representative of trams they show how the components of rail noise vary with speed, and confirm the importance of rail-wheel interaction on noise generation of rail vehicles at lower speeds. The shape of the curves and the relationships between the

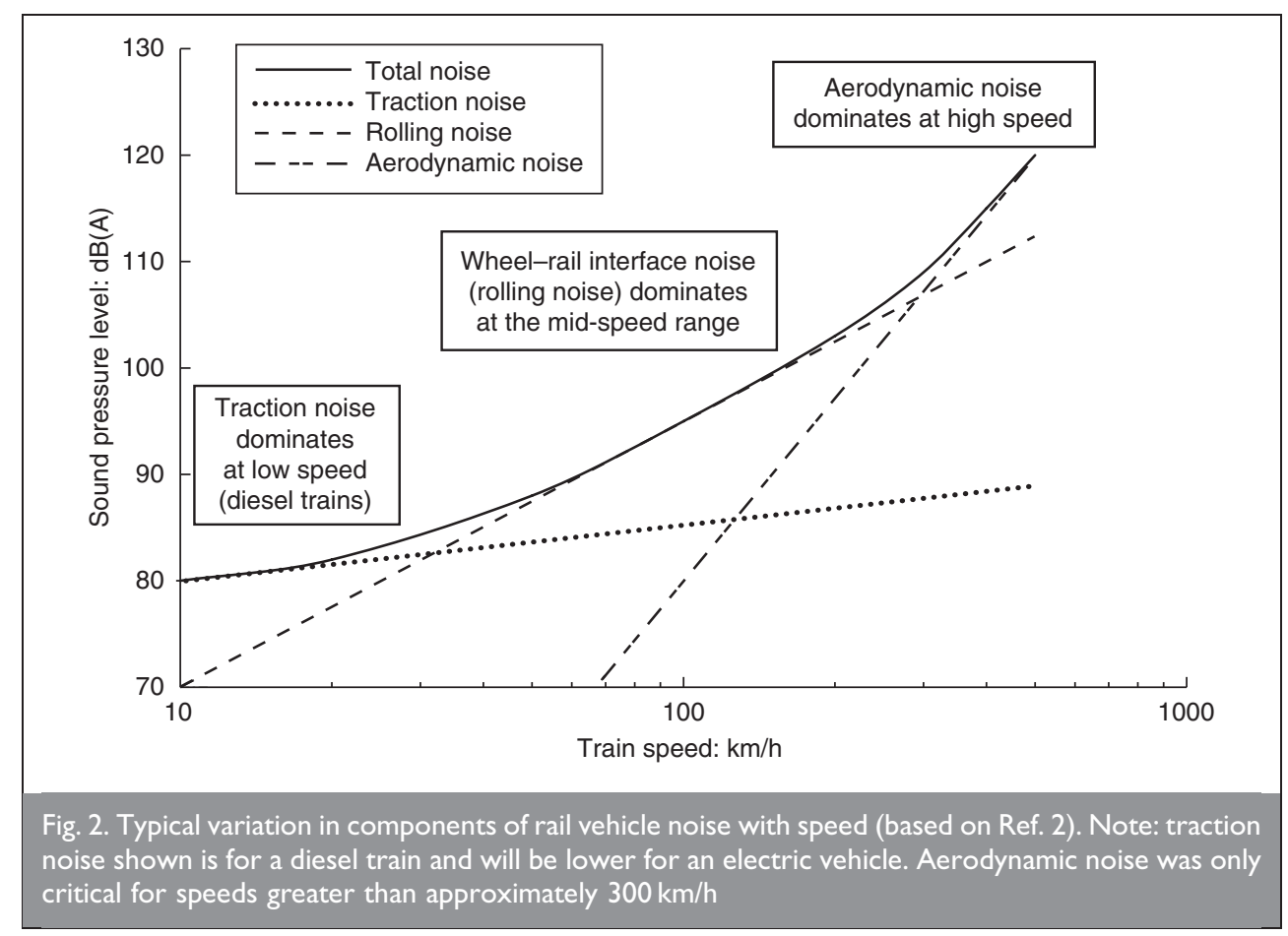


components shown in Fig. 2 will also be similar for diesel buses. (For more information on this and on transport noise in general the reader is directed to Ref. 3.)

Road noise tends to be constant with traffic and presents a relatively even level of intrusive noise to add to the background ambient noise level. Railway noise tends to be 'peaky' and comes in noise periods during the passage of a train, followed by periods of normal local ambient noise. Perception studies of such noise, used to derive intervention levels in standards, suggest that constant (traffic-type) noise is generally regarded as more intrusive than periodic (rail-type) noise, and that people become more familiar with regular periodic noise, and tune it out, thus finding it less intrusive. ${ }^{4}$ This has led to what is called the 'railway bonus' within standards whereby intervention levels for periodic noise are normally greater than those for traffic noise, with a $3-5 \mathrm{~dB}(\mathrm{~A})$ 'bonus' being quoted.

\section{TYPICAL NOISE ASSESSMENTS PERFORMED FOR TRANSPORT AND CODES}

The majority of noise assessments undertaken for transport schemes normally revolve around assessing likely noise effects during design as part of the overall environmental assessment process, or assessing the scheme influence post-construction. Now, however, there are requirements to assess the environmental noise across the country through the generation of national environmental noise maps, the production of which is required under European law.

For new transport schemes the prediction and measurement of noise is based on set techniques included in standards, namely the Calculation of Road Traffic Noise $e^{5}$ and the Calculation of Railway Noise. ${ }^{6}$ These prediction and measurement methods are assessed relative to noise dose limits over set time periods $\left(\mathrm{La}_{10}\right.$ or $\mathrm{La}(\mathrm{eq})$ values), that act as trigger levels for pre- or post-scheme designed insulation, mitigation and compensation.

Other standards related to noise emissions from industry and suggested noise planning limits for new houses and developments also exist ${ }^{7}$ (although this is currently under review). European and World Health Organisation (WHO) guidelines ${ }^{8}$ have also been produced (the WHO guidelines are widely considered to be onerous and are currently difficult to achieve/maintain in most urban areas). These documents relate to values of $\mathrm{La}_{(\mathrm{eq})}$ and $\mathrm{La}_{(\max )}$, normally assessed $1 \mathrm{~m}$ from a qualifying window of an affected property. However, it should be noted that there are no statutory maximum transport noise limits.

\section{COMPARISONS BETWEEN MODES AND PREVIOUS WORK}

From the above it can be seen that the majority of noise assessments are scheme specific. Few comparisons between the general vehicle impacts between modes have been produced from these scheme studies, and these can be difficult and subjective due to the different nature and location of the scheme-specific surveys and the factors that influence the localised noise generated and its measurement.

Some studies have been produced that compare the peak noise generated between vehicles; however, the use of peak noise for comparisons is known to have difficulties. ${ }^{4}$ Other studies have compared average noise values and such average values tend to be more appropriate in defining the overall scheme effects and perceived intrusiveness. Again comparison between modes on $\mathrm{La}_{(\text {(eq) }}$ values alone tend to be highly scheme specific.

Significantly, where trams or guided bus schemes have been proposed one of the major causes of public concern has been that the schemes would be considerably noisier than normal buses or current traffic. As noise is subjective, however, the perception of comparative noise can be very difficult to assess, especially when the characteristic sound frequency, duration and level of occurrence of the emissions can be widely different.

From the limited studies that have been produced it has been found that buses are generally as noisy as trams. ${ }^{9,10}$ More recently, however, a group in Nottingham who were opposing the extension of the NET system have produced reports which claim that trams are more noisy than buses and could potentially have significantly greater effect than any bus-based transport solution, ${ }^{11}$ although these are believed to be based on peak noise assessments $\left(\mathrm{La}_{(\max )}\right)$.

Within the prediction method for rail noise, ${ }^{6}$ vehicle pass SEL values are used as the basis of the assessment method to allow comparison between different vehicles. The advantage of SEL values is that they can easily be compared between different noise events and added into ambient noise data to allow new $\mathrm{La}_{(\mathrm{eq})}$ average noise dose to be defined. Therefore, a comparison of SEL of vehicle pass offers a way forward in making a comparison between operational criteria of different modes.

Bus and car noise in particular is normally assessed as part of general traffic noise and seldom distinguished as separate noise sources. With the development of proposals for guided bus systems the prediction procedures for railway noise have been used for buses and some work to define SEL values has been performed and is further discussed below. ${ }^{12}$

Some limited data on SEL values for different modes or operational circumstances do, however, exist. Calculation of Railway Noise ${ }^{6}$ includes an SEL for Sheffield trams (measured in highly controlled circumstances in free field on ballasted track at speed) as $74 \mathrm{~dB}(\mathrm{~A})$ at $25 \mathrm{~m}$ (equating to $79 \mathrm{~dB}(\mathrm{~A})$ at $7 \cdot 5 \mathrm{~m}$ ). Within Ref. 6, additional correction factors were then added to give a predicted impact at any location. Analysis of the limited data available from Ref. 11 suggests they have used a tram noise equivalent to an SEL of $86 \mathrm{~dB}(\mathrm{~A})$ at about $8 \mathrm{~m}$ distance.

\section{DATA COLLECTION METHODOLOGY}

To allow comparisons between various modes a series of noise readings have been made across a range of operational circumstances for the passage of buses, trams and cars. The majority of the work has been performed in the Greater Nottingham area.

Measurements of the passage of the above vehicles have been made to evaluate the SEL value for each vehicle pass assessed. The method used has been adapted from that proposed to assess vehicle SEL for rail vehicles ${ }^{6}$ and similar to that used to assess guided buses in Leeds for the assessment of the Leigh Busway. ${ }^{12}$ Readings of noise were stored using the logging and data storage 
system within a Bruel and Kjaer integrating noise meter. This allows the $\mathrm{La}_{(\mathrm{eq})}, \mathrm{La}(\max )$ and SEL for vehicle passes to be assessed for the duration of the readings, and further analysis of elements within the data to be performed to assess individual vehicle pass SEL.

As far as practical, measurements were made on level ground as close to free field conditions as possible, in order to remove the effect of adjacent buildings. Areas with low ambient noise relative to the noise pass measured were chosen with readings made at the times of day where other noises were unlikely to unduly influence the readings. The noise meter was set typically 1 to $1.5 \mathrm{~m}$ above ground level at $90^{\circ}$ to the direction of travel of the vehicles under measurement. Readings were taken on clear days with limited wind, over the winter and spring period, with the meter set to fast reading and A weighting.

For comparison, SEL measurements of vehicle passes were taken between 5 and $20 \mathrm{~m}$ from the side of the vehicle; the majority of readings were made between 5 and $12 \mathrm{~m}$ from the vehicles. These readings were normalised using a line source distance correction to a distance of $7.5 \mathrm{~m}$ from the edge of the vehicle. This distance was chosen as in urban environments it is frequently difficult to find sites where readings at a distance of $25 \mathrm{~m}$ from the sources (as suggested in Ref. 6) can be made. A large number of vehicle passes for various operational circumstances were measured and SEL at $7 \cdot 5 \mathrm{~m}$ for each case assessed.

\section{OPERATIONAL CIRCUMSTANCES AND DATA COLLECTION ISSUES}

To allow a comparison between modes a typical range of operational circumstances were identified. For buses and cars these consisted of arriving and accelerating away from a stop, travelling at constant traffic speed of around $30 \mathrm{mph}$ on flat ground, travelling at low speed, and under hard acceleration. For trams, assessment of travelling at speed on ballasted segregated track $(50 \mathrm{mph})$, travelling at road speed in street running $(30 \mathrm{mph})$, travelling slowly over point work on ballasted track, travelling slowly on street track in pedestrian areas, and arriving and leaving stops/accelerating was made. Some measurements were made at a number of locations where both buses and trams use the same streets (see Fig. 3). Measurement of other vehicle noises such as brake compressor evacuation and warning bells was also made.

The Nottingham trams assessed in this work are 100\% low-floor Bombardier Incentro vehicles approximately two to three years old, and they are typical of modern trams. Measurements of tram noise were consistent at all sites with little difference between each vehicle pass measured. This was due to the low contribution of traction noise and the more consistent nature of the driving. Average values of SEL for each operational circumstance were assessed, and it should be noted the average SEL was based on power levels, not the numerical average of the $\mathrm{dB}(\mathrm{A})$ values.

Assessments of buses and cars were made at a number of locations to assess the passage of vehicles at road speed and where they leave a stationary position (Fig. 4). Car noise was measured on free-flowing urban through roads, outside the peak hours, where traffic was running in the region of the road speed limit. Measurements of cars pulling away from a stop were made at
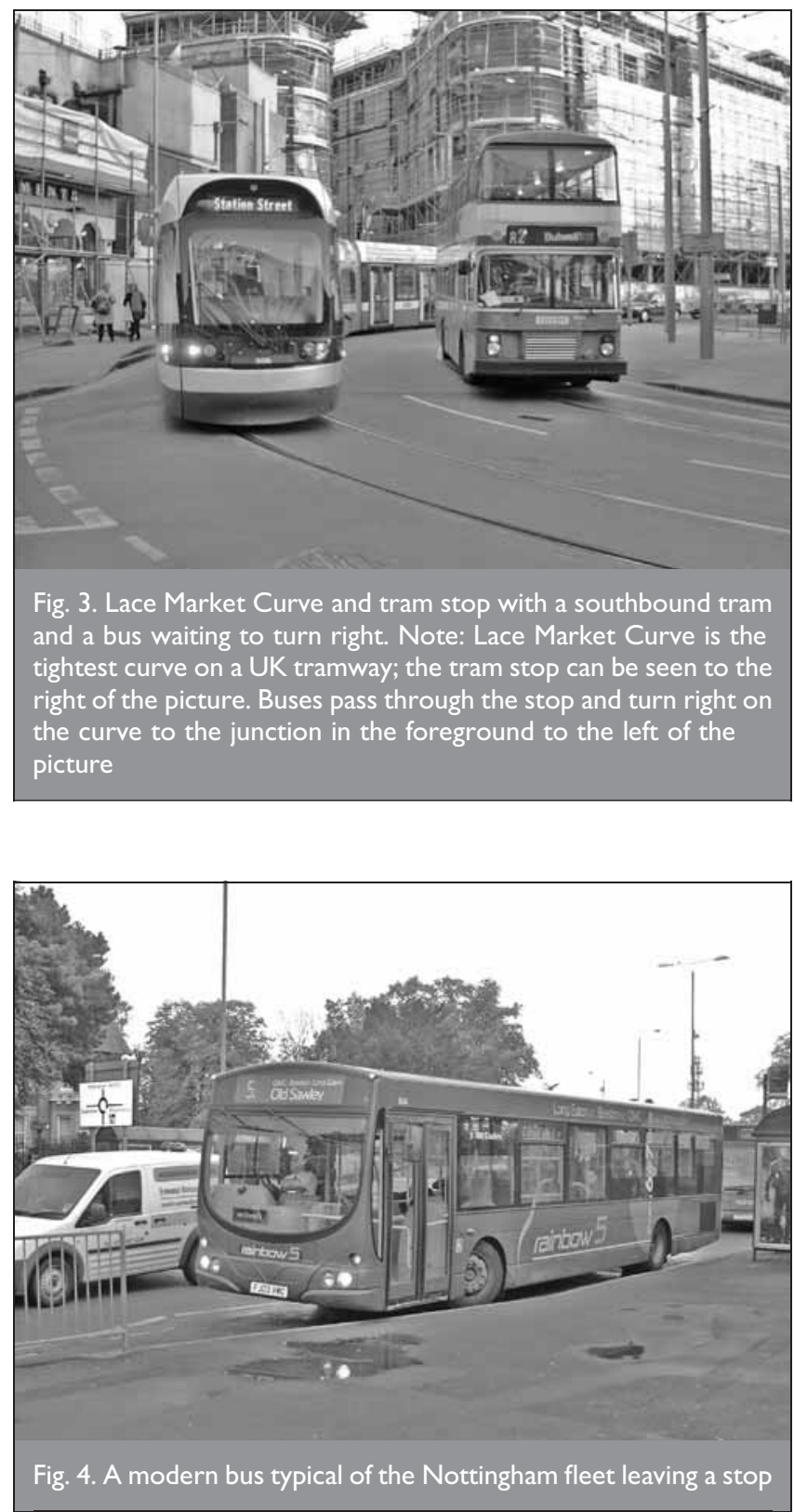

junctions. The typical vehicle speeds assessed were based on knowledge of the traffic conditions and timing the cars over set distances.

The bus fleet in Nottingham is generally modern and in the majority of cases these buses were measured (Fig. 4). The measurements of consistent bus/car noise data were occasionally quite problematic due to the manner in which the vehicle was driven and the contribution of engine noise (i.e. if a vehicle was accelerating, under constant power or coasting). In addition, as buses and cars form part of the general flow of traffic the isolation of the noise measurement from adjacent vehicle noise was occasionally difficult and made taking measurements time-consuming. Therefore for buses and cars, due to the variability of engine noise, average SEL values are presented across a range.

\section{ASSESSMENT OF DATA COLLECTED AND DISCUSSION}

Summary SEL values from the data collected across the range of circumstances are presented in Tables 1 to 3. The graphs in the 


\begin{tabular}{|lccc|}
\hline Operation condition & Tram & Bus & Car \\
\hline At speed $(30 \mathrm{mph})$ & 86 & $82(77-84)$ & $77(75-80)$ \\
Slow (I0-15 mph) & 82 & $82(75-84)$ & $73(68-77)$ \\
Leaving a stop & 81 & $83(79-85)$ & $79(76-82)$ \\
Accelerating hard from a stop & 82 & $87\left(\mathrm{SEL}_{(\max )}\right)$ & $82\left(\mathrm{SEL}_{(\max )}\right)$ \\
Waiting at stop/idling & Ambient $\left(\mathrm{La}_{(\mathrm{eq})}\right)$ & $72 \mathrm{La}_{(\mathrm{eq})}(68-73)$ & $55 \mathrm{La}_{(\mathrm{eq})}$ \\
& (limited emission) & & \\
& & & \\
\hline Table I. On-street vehicle pass, average SEL (dB(A)) normalised to $7.5 \mathrm{~m}$ (plus (range))
\end{tabular}

the busy Lace Market Tram stop on NET (Figs 3 and 6), bus engine noise drowned out concurrent tram noise.

When leaving and arriving at stops the limited influence of the tram traction noise became apparent, and the tram noise became comparatively quiet and progressive in comparison with buses (Fig. 6). The effect of

\begin{tabular}{|lc|}
\hline Operation condition & $\mathrm{La}_{(\max )}: \mathrm{dB}(\mathrm{A})$ \\
\hline Tram warning bell & 87 \\
Tram door warning & 80 \\
Bus break evacuation limit & 72 \\
Max bus noise measured & 93 \\
Max tram noise measured & 87 \\
Max car noise measured & 84 \\
& \\
Table 2. Other operational noise levels (peak values, $\left.\mathrm{La}_{(\max )}\right)$ \\
\hline normalised to $7.5 \mathrm{~m}$
\end{tabular}

accompanying figures show typical samples of data collected at a few of the locations assessed.

Table 1 shows a comparison of trams, buses and cars in street operation; it can be seen that at a speed of $30 \mathrm{mph}$ the trams generated a higher SEL value ( $86 \mathrm{~dB}(\mathrm{~A}))$ than both buses and cars, mainly due to rail-wheel interaction noise. Bus noise was variable at this speed due to the influence of engine noise; however, at the top end of the SEL range, buses would not be significantly quieter than trams. The bus values measured at speed compare well to the SEL values measured for the assessment of guided buses. ${ }^{12}$ These evaluations appear to be sensible as the European Union sets standards for the noise emissions of buses on a drive-by, at constant speed and engine revs, in controlled conditions at $80 \mathrm{~dB}(\mathrm{~A}) \mathrm{La}_{(\max )}$ at $7.5 \mathrm{~m}$ from the bus centreline. ${ }^{13}$ The noise from cars passing at $30 \mathrm{mph}$ was generally consistent (see Fig. 5) and an average SEL of $77 \mathrm{~dB}(\mathrm{~A})$ was assessed.

At slower speeds the difference between trams and buses became much less significant with similar SEL values. However, buses did show some higher SEL values, due to acceleration, than the more consistent tram SEL values, in contrast to the situation at speed. On street track, at low speed, the tram could barely be distinguished above adjacent buses and on measurements made at

\begin{tabular}{|lll|}
\hline Operation condition & Tram: $\mathrm{dB}(\mathrm{A})$ & Guided bus: $\mathrm{dB}(\mathrm{A})$ \\
\hline At speed & $79(50 \mathrm{mph})$ & $79(30 \mathrm{mph})$, \\
& & $83(50 \mathrm{mph})$ \\
Low speed (I0-15 mph) & 76 & 78 \\
Leaving stop & 78 & 82 \\
Point work slow & 80 & $\mathrm{~N} / \mathrm{A}$ \\
& \\
Table 3. Comparison of vehicle passes SEL (dB(A)), segregated \\
track (ballasted track versus guided bus) normalised to $7.5 \mathrm{~m}$. \\
(Guided bus based on Ref. I $)$
\end{tabular}

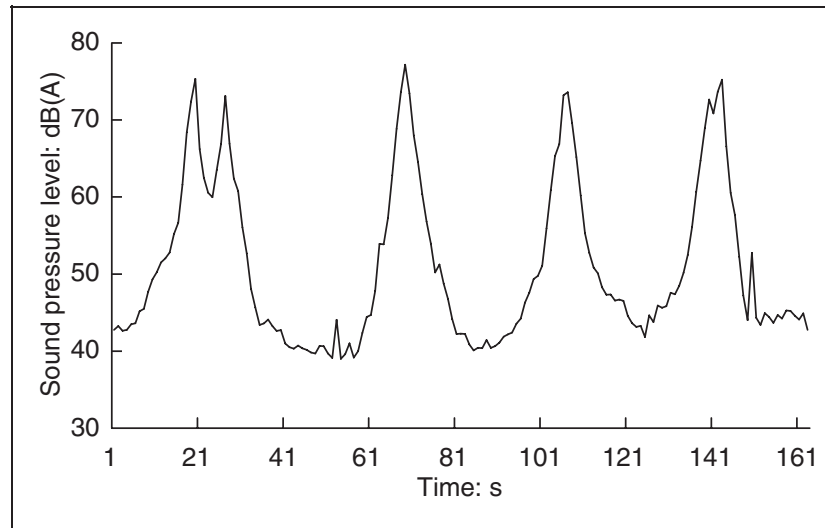

Fig. 5. Typical raw data measured for the pass of five cars, travelling at approximately $30 \mathrm{mph}$ at $7.5 \mathrm{~m}$ distance

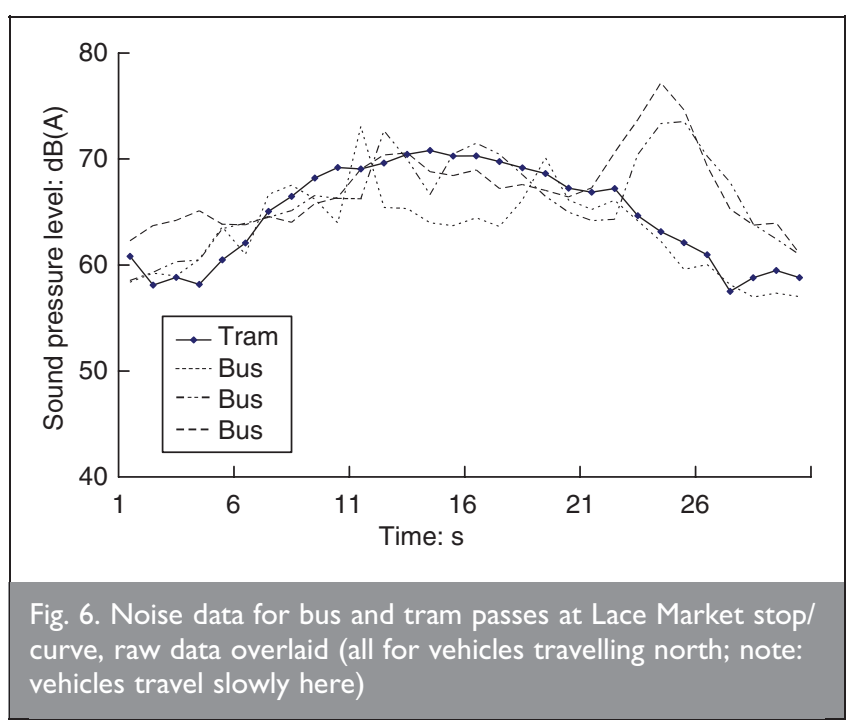




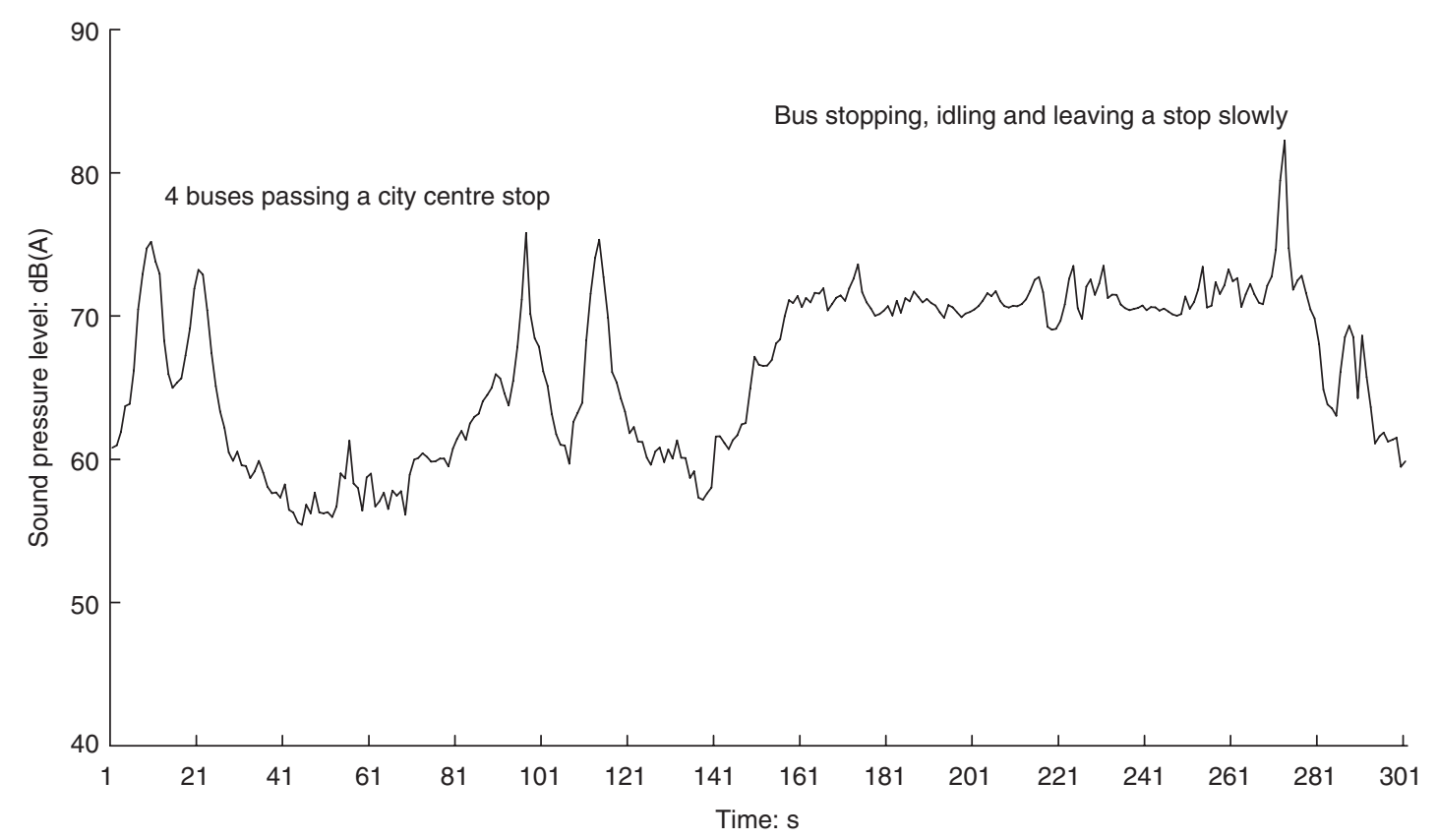

Fig. 7. Raw data for buses passing and stopping at a city centre stop. (The stop is in a lay-by; measurements made $7.5 \mathrm{~m}$ from lay-by)

When about to leave stops, the trams sound warning buzzers on the doors and these were assessed at about $80 \mathrm{~dB}(\mathrm{~A}) \mathrm{La}_{(\max )}$ at $7 \cdot 5 \mathrm{~m}$. Often trams sound their bells in order to warn people of imminent departure and this bell noise is designed to be intrusive but is described as being 'a polite bell' rather than a warning horn-type sound. This was measured at $87 \mathrm{~dB}(\mathrm{~A}) \mathrm{La}_{(\max )}$. Both of these warning sounds on trams are required by law. The tram bell was the noisiest peak tram reading measured during this research (Table 2).

Although not assessed in detail as part of this study, some readings of delivery vehicles were taken as they passed. In general these were noisier than both trams and buses and measurements of the passage of 'black cab'-type taxis generated a surprisingly large noise, significantly more than cars and approaching that of buses.

Table 3 shows the data from measurements made of trams travelling on ballasted track. These data have been compared to

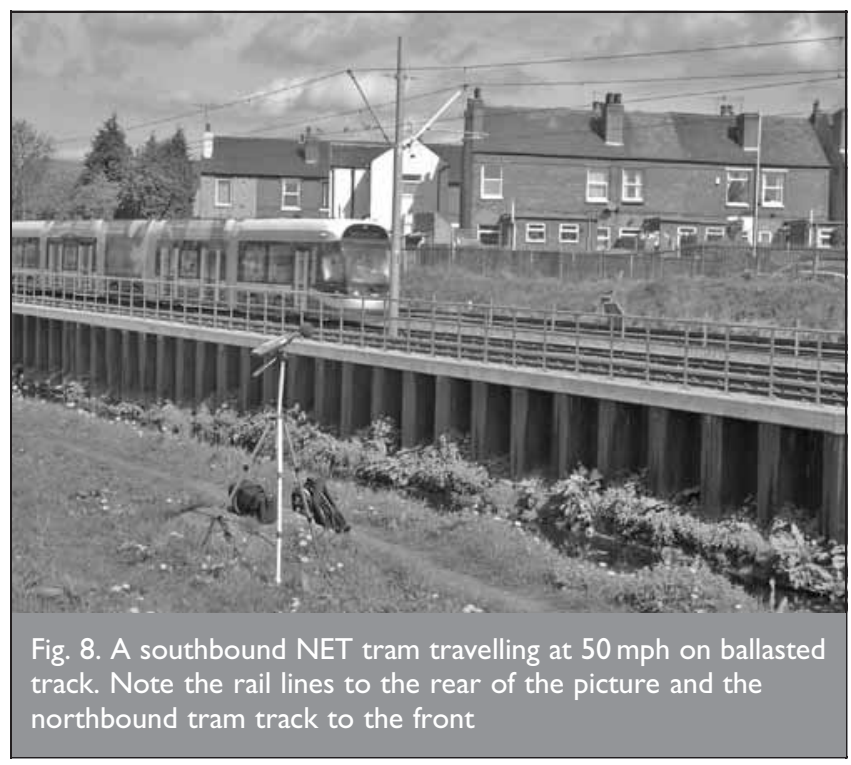

data produced for guided bus systems ${ }^{12}$ as it is considered appropriate to compare both as totally segregated modes. The tram SELs at speed ( $50 \mathrm{mph}$ ) were quieter than those measured on street track, and similar to that generated by guided buses; however, the speed of the buses was some $20 \mathrm{mph}$ slower, and at equivalent speed (50 mph) the bus was noisier.

Figure 8 shows the site where measurements of trams travelling at speed on ballasted track were made on the Nottingham NET system; a further set of tracks for the Network Rail Robin Hood Line can be seen in the background. Fig. 9 illustrates a typical set of data showing the passage of a southbound tram, northbound tram, a diesel train and a further southbound tram. For general interest, the data to the right of the curve show the barking of a small dog some 15 to $20 \mathrm{~m}$ from the meter. When normalised back to $7 \cdot 5 \mathrm{~m}$ these vehicle passes gave SEL values of 79, 79, 90 and $77 \mathrm{~dB}(\mathrm{~A})$, respectively, and distance-corrected peak values of 75, 76, 88 and $73 \mathrm{~dB}(\mathrm{~A})$. The uncorrected SEL and $\mathrm{La}_{(\max )}$ for the dog were 85 and $85 \mathrm{~dB}(\mathrm{~A})$, respectively. These values also accord well with the SEL of the older Sheffield trams. ${ }^{6}$

At slower speeds and at stops, the trams on ballasted track remained quieter than buses (see Table 3 ) as again it is bus traction noise that forms the largest component. Leaving stops, the trams generated slightly more noise than at low speed on ballast; this was considered to be due to ground reflection effects as concrete slab track was used through tram stops. The noise of the trams through the point work was relatively high in comparison with the slow speed measurements. It is clear therefore that rail-wheel interaction and track-bed was a key issue in tram noise control.

\section{THE IMPORTANCE OF TRACK AND PAVEMENT DESIGN AND MAINTENANCE}

Tram noise was noticeably lower on ballasted track than on street track when travelling at speed, but it has to be considered that in 


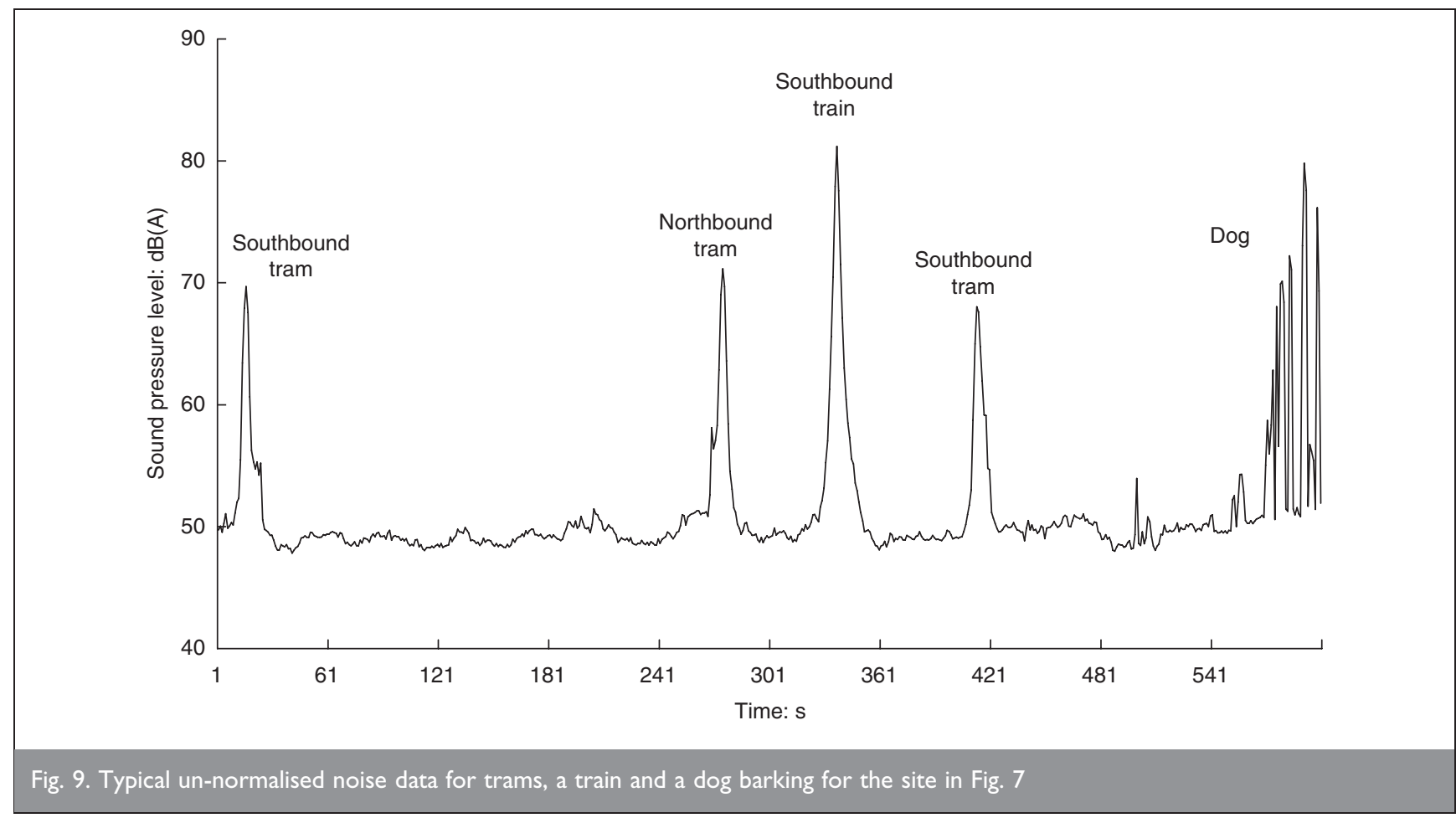

some specific operational circumstances and conditions other local system noises, such as tram noise from wheel squeal and wheel interaction on worn or poorly designed point and crossing systems, may significantly exceed the values measured in this work. In Nottingham, difficulties have been experienced with some of these factors, and although the wheel squeal problem seems to have been solved there is still significant noise emanating from a diamond track crossing and from point work. Noise levels may also increase if adequate rail condition and wheel profile shape (to optimise interaction) are not maintained, although techniques do exist to minimise and control these effects.

Although bus wheel-road interaction only becomes significant at high speed, pavement type and road condition can have significant effect on the noise levels produced by buses. Guided buses typically run on precast or slip-formed concrete guideway pavements, and on some systems the finish of the pavements has led to significant problems with ride quality, noise and guidance. Despite this, the noisier concrete finishes seem to be preferred because they support the concentrated and channelled loads better than less wear-resistant, low-noise surfaces.

\section{I0. COMPARISONS BETWEEN MODES}

From the above it can be seen that in the round, across all conditions, the noise from buses is potentially no more significant than that from trams. Bus engine noise, especially under heavy acceleration, can generate larger noise emissions than trams, but under certain conditions trams do generate more noise than buses, for example on street track at speed. Cars as expected are quieter than both modes although, again under aggressive driving, cars can also generate significant noise impact.

If the effect of overall service noise is considered by comparing relative noise effects between the SEL values, the passage of eight cars at $30 \mathrm{mph}(77 \mathrm{~dB}(\mathrm{~A})$ ) gives a combined SEL of $86 \mathrm{~dB}(\mathrm{~A})$, which is equivalent to the tram at $30 \mathrm{mph}$ on the street, and similarly three to four cars equate to the SEL measured for one bus. Three buses at $81 \mathrm{~dB}(\mathrm{~A})$ SEL equate to one tram at $86 \mathrm{~dB}(\mathrm{~A})$ at speed. The situation becomes somewhat reversed when considering trams at slower speeds (e.g. when leaving stops), or when they are at speed on ballasted track. In such circumstances two to three tram passes equate to the noise from the equivalent passage of one bus. This becomes significant at high flow rates as trams carry four times as many passengers as a bus. Typical tram services run at $10 \mathrm{~min}$ frequencies in each direction, giving a total passage of 12 trams/h in a given area. To provide the same level of passenger capacity this would require in the region of 50 buses (a bus every 2 to 3 min each way) with the consequent effect on noise.

From the above it can be seen that the regular passage of cars can have significant influence on noise in the urban environment, relative to buses and trams, which pass by at lower frequencies.

\section{CONCLUSIONS}

(a) The use of SEL to compare noise generated between vehicles seems appropriate and methods are available to achieve this.

(b) The main components of noise from trams and buses are wheel-rail interaction and engine noise under acceleration, respectively.

(c) Consideration across a wide range of operational circumstances reveals there is little perceivable difference in the magnitude of noise generated by trams or buses as general modes.

(d) Localised differences do exist such that buses accelerating are noisier than trams, and trams at speed (on street track) are louder than buses under constant power.

(e) Guided bus operations have the potential to generate similar or greater noise than trams (on ballasted track) when operating as segregated modes. However, local 
circumstance may generate higher localised noises from light rail.

( $f$ ) Adequate design of pavement surfaces and engine maintenance for buses and suitable design and maintenance of the track, track-bed and the rail-wheel interface for trams is required to limit noise emissions.

(g) Cars are generally quieter than trams and buses, yet when consideration of the frequency of various services is made, the car can generate significant noise emissions. This means that when trams or bus services are added to streets with moderate through traffic, little change in overall noise $\left(\mathrm{La}_{(\mathrm{eq})}\right)$ may ensue.

\section{REFERENCES}

1. BRUNel AND KJAER. Environmental Noise Measurement. Brunel and Kjaer, Naerum, Denmark, 2006. See http:// www.bksv.com/pdf/Environmental_Noise_Measurement.pdf (las accessed September 2007).

2. GAUTIER P. E. Railway noise: a review of recent progress and research. Proceedings of Euronoise 2003, Naples, Italy, 19-21 May 2003. Acoustical Society of Italy (AIA), Rome, Paper 494.

3. Rust, A. CALM, Noise Technology Status Report (2003), Community Noise Research Strategy Plan. Calm Network on Transport Noise of the European Union, Brussels, 2003.

4. Department For Transport. Railways Noise and Insulation of Dwellings. Her Majesty's Stationery Office, London, 1991, Report of the Mitchell Committee.
5. Department for Transport and Welsh Office. Calculation of Road Traffic Noise (CTRN). DoT and Welsh Office, Her Majesty's Stationery Office, London, 1988.

6. Department for TRANSPORT. Calculation of Railway Noise (CRN). Her Majesty's Stationery Office, London, 1995.

7. Department for the EnVIRonment. PPG24. Planning Policy Guidance 24: Planning and Noise. Her Majesty's Stationery Office, London, 1994.

8. World Health Organisation. Guidelines on Community Noise. WHO, Geneva, Switzerland, 1999.

9. Hass-Klau C., Crampton G., Biereth C. and Deutsch V. Bus or Light Rail: Making the Right Choice, 2nd edn. ETP/Bergische Universtät, Wuppertal, 2003.

10. Staiano M. Comparison of Light Rail and Bus Transit Noise. Transportation Research Record, 2001, No. 1756, 45-56.

11. Better Community Transport Group. Submissions to Department for Transport. Documents released under the Freedom of Information Act, 2006. See http:// www.dft.gov.uk/stellent/groups/dft_foi/documents/ divisionhomepage/611554.hcsp (last accessed September 2007).

12. Hyder Limited. GMPTE, Leigh Busway-Noise Methodology. Hyder Limited, London, 1999, Report produced for GMPTE: report NH20111|R|RT|L013|V3.

13. EURopeAn Union. European Union Directive (70/157/EEC), Permissible Sound Levels from Motor Vehicles. European Commission, Brussels, 1970.

\section{What do you think?}

To comment on this paper, please email up to 500 words to the editor at journals@ice.org.uk

Proceedings journals rely entirely on contributions sent in by civil engineers and related professionals, academics and students. Papers should be $2000-5000$ words long, with adequate illustrations and references. Please visit www.thomastelford.com/journals for author guidelines and further details. 